\title{
Introduction: Revisiting Garland Allen's Views on the History of the Life Sciences in the Twentieth Century
}

\author{
MICHAEL R. DIETRICH \\ Department of Biological Sciences \\ Dartmouth College \\ Hanover, NH 03755 \\ USA \\ E-mail: Michael.Dietrich@Dartmouth.edu
}

The essays in this issue originated from a conference held at Washington University, St. Louis in order to reflect on Garland Allen's contributions to the history of biology and to revisit his 1975 book, Life Science in the Twentieth Century. Gar's influence in the history of biology is of course beyond question. Everett Mendelsohn's essay on Gar begins this issue with an appreciation of his many different contributions as a teacher, historian, and activist. Jane Maienschein follows with a careful reconsideration of Thomas Hunt Morgan, the subject of Gar's landmark biography published in 1978. Maienschien seeks to bring Morgan back to his embryological foundations and away from the accolades he garnered through Drosophila genetics. Building on Gar's work in the history of genetics, Kim Kleinman's essay considers how Edgar Anderson's work from the Missouri Botanical Garden challenged the evolutionary genetics of Theodosius Dobzhansky and Ernst Mayr. John Beatty's essay takes a different approach to the history of evolutionary genetics by exploring the early debates over the relative importance of natural selection and mutation. Issues of the history of race and eugenics occupy the essays of Paul Farber and Diane Paul. Farber offers a perspective on the debate between Theodosius Dobzhansky and Ashley Montagu on the usefulness of the idea of race in scientific research, while Paul offers an insightful historiographic assessment of work on American eugenics, a topic to which Gar contributed heavily. In his essay, William Bechtel picks up on the theme of holism from Life Science in the Twentieth Century to develop an account of the search for mechanisms of circadian rhythms. Richard Burkhardt's essay rounds 
out this special issue with his own reflections on historical research and his discovery of a letter from his subject Niko Tinbergen to himself that Tinbergen never sent. Naturally, we gave Gar the last word. His reflections on the impossibility of revising Life Science in the Twentieth Century don't diminish his accomplishments, but, in characteristic form, highlight Gar's thoughtfulness and commitment to the process of historical research while celebrating the tremendous advancement of the history of biology as a field since 1975 . 